\title{
APRENDRE LA LITERATURA CLÀSSICA A TRAVÉS DE L'ART: L'OBRA DE L'ARTISTA I IL·LUSTRADOR JOMA*
}

\author{
MONTSERRAT CAMPS GASET \\ Universitat de Barcelona \\ mcamps@ub.edu \\ ORCID: 0000-0001-8486-6036
}

RESUM

L'il-lustrador Joma (Josep M. Rius Ortigosa) ha utilitzat molt sovint la literatura clàssica en les seves obres. Fa anys va il-lustrar la Ilíada i l'Odissea en vinyetes publicades a La Vanguardia, i darrerament ha tingut iniciatives innovadores com les d'organitzar "sopars de l'Odissea", en què ha unit dibuix, paraula i gastronomia, o representacions de les Metamorfosis d'Ovidi que combinen el text, la il-lustració i la música. Aborda aquestes iniciatives amb esperit crític que, en el món de l'ensenyament, es pot utilitzar amb èxit, combinant disciplines diferents com són la música, la literatura, el llatí i el grec i l'art plàstica.

PARAULES CLAU: il·lustració clàssica, art i educació, tradició clàssica.

\section{LEARNING CLASSICAL LITERATURE THROUGH ART: THE WORK OF THE ARTIST JOMA}

\section{ABSTRACT}

Josep M. Rius Ortigosa is an artist, draftsman and illustrator who often refers to Classical Literature in his works. Years ago, he drew the Iliad and the Odyssey in cartoons published in the newspaper La Vanguardia. Recently he organised the 'Dinner with the Odyssey', an artistic initiative involving text, drawings, and gastronomy. He has also created a performance on Ovid's Metamorphoses, combining the text with pictures, dancing, and music. He develops a critical approach towards ancient texts, which, together with his artistic performances, could be successfully used in education, since he combines different disciplines such as music, literature, Greek and Latin, and art.

KEYWORDS: Classical illustration, art and education, Classical tradition.

L'artista J. M. Rius Ortigosa (Barcelona, 1954) va estudiar a l'escola d'Arts i d'Oficis, i també es va llicenciar en Periodisme i diplomar en Història. Ha dedicat la seva carrera a la il·lustració, per editorials i també per diaris i revistes com Cavall Fort i Serra d'Or, entre d'altres. Fa anys, va tenir molt d'èxit amb les contribucions a La Vanguardia en què reproduïa textos grecs d'Homer i, en els darrers temps, ha dut a terme diverses activitats relacionades amb la literatura grega i llatina.

D'entrada, el seu interès pel món clàssic sorprèn, ja que no va tenir una formació específicament clàssica. Ell explica que, a casa seva, el seu pare,

\footnotetext{
* La data de consulta de totes les referències d'Internet donades aquí és 30 de juliol de 2019.
} 
després de sopar, s'asseia a taula per llegir Homer amb un llapis i un diccionari al costat, d'una manera molt solemne, i que aquest és un record que li ha quedat tota la vida perquè li feia molta impressió. Quina era, es preguntava ell, aquesta obra tan important a què el seu pare dedicava tants miraments? Així es va iniciar en el coneixement de les obres clàssiques i les va convertir en tema de la seva producció artística.

Al diari La Vanguardia, des del 2007 fins al 2009, publicà setmanalment (en el Magazine del diumenge) una sèrie d'il-lustracions que explicaven l'Odissea, amb la particularitat que inclö̈en versos en grec. ${ }^{1}$ Atès que ell mai no va aprendre grec, l'alfabet li resultava un repte artístic: no escrivia en grec, sinó que dibuixava les lletres, amb una precisió sorprenent, això sí. ${ }^{2}$ La resposta del públic davant una empresa tan arriscada fou excel-lent, i un cop acabada la sèrie de l'Odissea, emprengué la de la Ilíada, a partir del 2009, en el mateix diari, i després féu una breu sèrie de faules d'Isop. ${ }^{3}$

La reacció positiva que tingueren aquestes il-lustracions en aquell moment ja propicià que se'n fes un ús didàctic a les aules i que servís per cridar l'atenció dels estudiants sobre aquesta interpretació contemporània d'un clàssic. Per exemple, a l'Institut de Premià de Mar, per iniciativa de la professora Margalida Capellà, l'il-lustrador visità els alumnes de llengües clàssiques, ${ }^{4}$ i abans havien pogut enregistrar el procés de creació d'una il-lustració sobre la Ilíada, en què explica les limitacions de l'espai i la importància de l'escriptura com a dibuix, perquè el text $\mathrm{s}^{\prime}$ integra en el dibuix. ${ }^{5}$

Amb aquestes il-lustracions homèriques es van fer exposicions itinerants per biblioteques del país, durant els anys 2013 i $2014 .{ }^{6}$ L'Odissea és, per a Joma, una obra fascinant, que li permet crear una interacció amb el món artístic i plàstic, que no es limita a ser una lectura de l'obra, sinó una creació artística sobre l'obra. Com a lector, el que més el fascina és el llenguatge d'aquestes obres clàssiques. A partir d'aquí, doncs, munta un seguit d'iniciatives que tenen com a punt de partida l'obra homèrica.

Així, temps després de les publicacions al diari, va muntar una exposició a l'hotel Alma, sobre l'Odissea, en paper. ${ }^{7}$ Ara bé, la gran experiència amb el paper

1 Vegeu-ne exemples al bloc d'en Joma: <http://joma-enbloc.blogspot.com/p/en-tempsdhomer.html>.

${ }^{2}$ Encara que sembli anecdòtic, això pot servir per explicar als alumnes el sentit original del

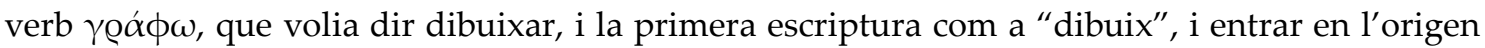
de l'escriptura i l'evolució dels signes gràfics que la representen.

3 Sobre aquestes iniciatives, vegeu-ne exemples i una explicació a <http://mediterraneo antiguo.blogspot.com/2014/01/entrevista-con-josep-maria-rius-joma-la.html>.

${ }^{4}<$ https://blocs.xtec.cat/elfildelesclassiques/2011/11/23/una-classe-de-grec-amb-joma $>$.

${ }_{5}^{5}$ Sobre la creació de la Ilíada: $<$ https://youtu.be/ItjpIdAGCw8> i <https://youtu.be/2vq_tYrkkuk>.

6 <https://youtu.be/V-M8cvoWBL8>; <https://bibliotecadevic.com/2013/10/01/exposicio-lodis sea-dhomer-una-recreacio-visual-de-joma $>$; $<$ https://blocs.xtec.cat/literaturagregaaescena/2014/03/ 31/lodissea-dhomer-una-recreacio-visual-de-joma> .

$7<$ www.almahotels.com/barcelona/en/movil-de-alma-joma $>$. 
la va fer al Molí de Capellades, l'Odissea "des del paper", que li va permetre desenvolupar la idea artística a mesura que es fabrica el paper mateix, és a dir, com una part d'aquest, i no fent-lo servir només com a suport, que és la manera habitual de relacionar-s'hi. D'aquesta manera, l'artista juga amb el format i el perímetre, lluny de les dimensions habituals d'un rectangle, i aconsegueix textures diverses tot incorporant pigments a la pasta i creant així també volum. No hi ha cap intervenció ni acabament posterior sobre el paper un cop s'ha assecat, de manera que el paper deixa de ser el suport per esdevenir l'obra mateixa. D'aquest projecte en va fer dues sèries, una de deu papers grans (entre un metre i mig i dos metres) i la segona, de tretze peces més reduïdes $(60 \times 80)$ on l'artista juga amb la filigrana. Paral-lelament, escriví texts per als dibuixos, que encara no han estat publicats. Per exemple, la figura 1 va acompanyada d'un text que diu:

Amb els ulls a les teves mans, cerques Ningú, Polifem eixorbat de l'únic ull que posseïes.

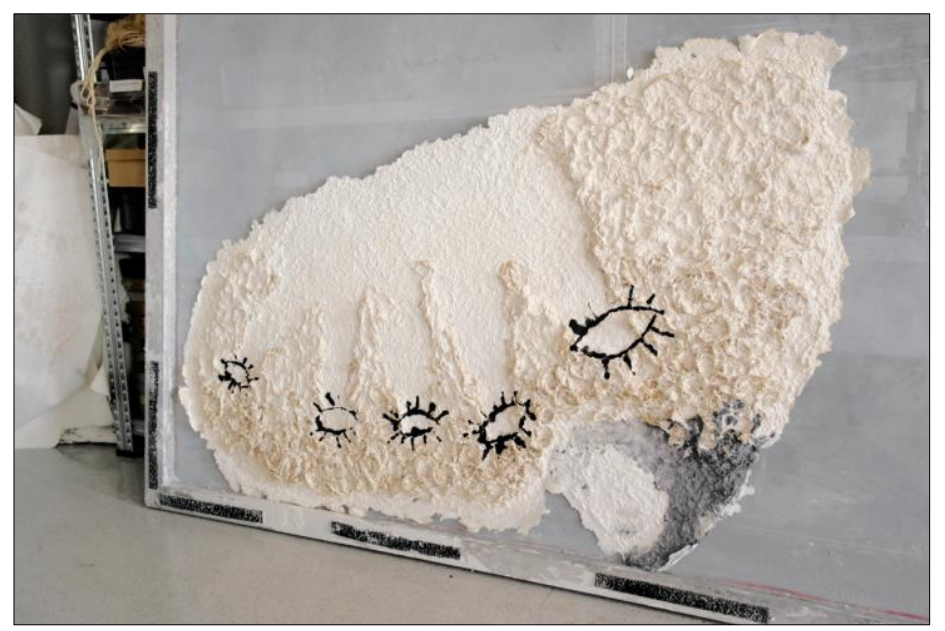

Fig. 1. Exemple d'un dibuix fabricat juntament amb el paper, a Capellades. Aquest porta el títol Ningú. Foto: Joma.

El treball sempre sobre l'Odissea el conduí a unes experiències, l'any 2016, amb el títol $L^{\prime}$ ona vinosa, ${ }^{8}$ en què practica una acció que després repetirà en un altre context, el sacrifici d'un "llibre intervingut". Consisteix a agafar un exemplar d'una traducció catalana de l'Odissea i pintar-ne cada pàgina -impresa o noamb un dibuix al-lusiu. ${ }^{9}$ A més d'aquest sacrifici, L'ona vinosa inclou la il-lustració en directe davant del públic, seguint el tema del vi a l'Odissea. L'experiència es dugué a terme en més d'una ocasió a Catalunya: en els actes de

\footnotetext{
${ }^{8}$ En els actes de Cervera, Vila del llibre: $<$ https://youtu.be/I450GWMCXEQ $>$; a Vilafranca del Penedès: <https://youtu.be/D8XIG7lmYJA>, i a Alella: <https://youtu.be/uhoh2qZVtVI>.

9 Es pot veure el procés d'intervenció d'un llibre a $<$ https://youtu.be/kw-GSnYi_cw $>$ i $<$ https://youtu.be/0Bc-RGDz0Sw>.
} 
Cervera Vila del Llibre, i a Vinseum, amb les caves Pere Ventura, ${ }^{10}$ amb un format semblant però sempre de manera diferent, perquè el llibre intervingut és un altre i les il·lustracions en directe també són diferents.

L'última experiència sobre l'Odissea ha inclòs un altre element molt relacionat amb el text homèric però molt original: el menjar. A Barcelona, el 2018, amb la col-laboració del restaurant Semproniana, portat per la cuinera Ada Parellada, Joma inicià una experiència ludicogastronòmica que tingué força continuïtat. Un cop al mes, se celebra un sopar per a deu comensals, en un reservat del restaurant, en companyia de l'illlustrador, que és l'onzè comensal, i on té lloc tota una experiència artística prèvia al sopar pròpiament dit. ${ }^{11}$

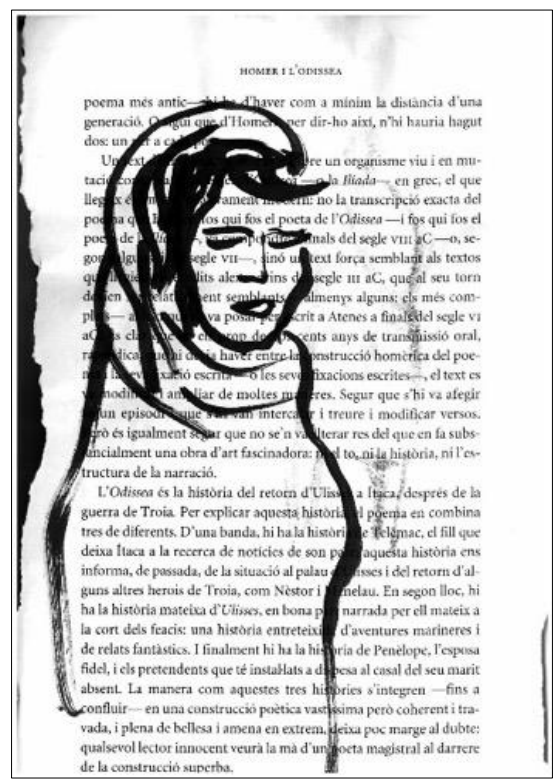

Fig. 2. Pàgina d'un llibre de l'Odissea intervingut i sacrificat. Foto: M. Camps.

Primerament, i mentre els comensals tenen a la mà una copa de bon vi negre, Joma du a terme el sacrifici d'un llibre preparat prèviament en els termes explicats del llibre intervingut. Diposita els fulls -les peces trinxades del sacrifici- sobre una gran plàtera i, a la manera homèrica, "els comensals allargaren les mans a les parts que tenien servides", és a dir, agafen els fulls del llibre (sempre amb dibuixos en tinta negra superposats al text imprès) i se'ls enduen, tants com volen (fig. 2). Un cop asseguts a taula, reben un menú amb noms creatius basats en l'obra homèrica, però que deixen traslluir molt el text homèric i no pas gens el contingut real, que els comensals suposaran o endevinaran com puguin. Per exemple, "les crestes d'orgull dels pretendents", "l'escuma irada de Posidó", "les mai congelades Sirenes", "els bunyols de tots

$10<$ https://youtu.be/5zVZgfDInCo $>$.

${ }^{11}$ Aquests sopars tingueren lloc periòdicament durant el 2018 i el 2019. Els esdeveniments de l'hivern del 2020 aturaren tota activitat lúdica o artística, però aquests sopars van néixer amb intenció de continuïtat i bona rebuda de públic, de manera que es podran recuperar quan sigui oportú. 
els vents d'Èol", o l'estrella del menú, el "plat antropofàgic del Cíclop (5 peces)". Aquí hi té molt a veure la imaginació culinària de la xef Ada Parellada, que porta el Semproniana i col-labora a l'èxit del sopar amb una cuina excelllent i fantasiosa. Quan els comensals, en un màxim de deu, han triat el menú (fent tota mena de conjectures), Joma explica el relat de l'Odissea a partir de cada plat triat (per tant, sense fer referència als que en aquell sopar concret no s'han escollit), i improvisa dibuixos sobre plats blancs de porcellana que després hom podrà, si vol, comprar. Al mateix temps, dibuixa sobre les tovalles els episodis que els plats evoquen, a partir d'un fil conductor que improvisa (fig. 3). El relat és oral, molt fidel a l'original de l'Odissea, però alhora improvisat, a la manera dels aedes que coneixen el tema i construeixen un relat diferent cada cop; ara bé, en el cas del sopar no és en vers. El relat i el dibuix s'improvisen alhora i decoren la taula. Un cop "explicats" els deu plats que han triat els comensals, i decorades per tant les tovalles, comença el sopar de debò, amb l'aparició dels plats reals que la capacitat inventiva de la cuinera ha reinterpretat. No és un exercici de cuina antiga, sinó de creativitat culinària i també artística. D'aquesta manera, la performance és única cada vegada, però el fil conductor sempre és $1^{\prime}$ Odissea. ${ }^{12}$

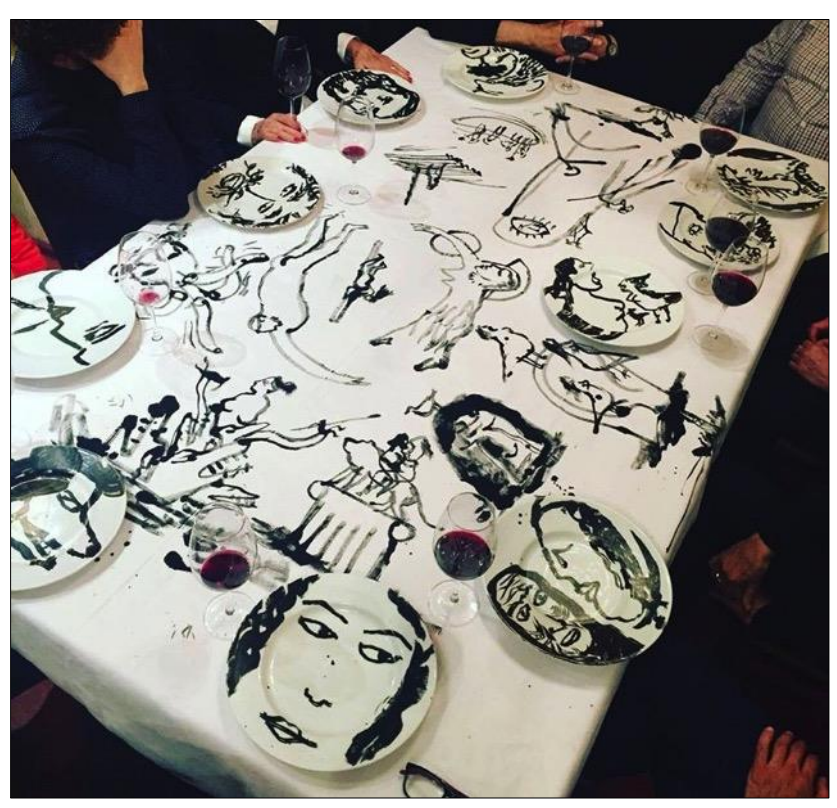

Fig. 3. Sopars de l'Odissea. La taula dibuixada en directe, just abans de començar a menjar. Foto: Joma.

L'experiència és complexa i elaborada, però en una altra escala, més senzilla, seria traslladable a altres ambients amb finalitat didàctica, tenint en compte que hi convergeixen tant la literatura - $\mathrm{l}^{\prime}$ aprenentatge de l'Odissea- com les arts plàstiques -la improvisació del dibuix amb tinta negra sobre suport blanc de tela o paper, o eventualment altres tècniques- com l'art teatral -la capacitat de

12 Vegeu la meva ressenya de l'experiència a <www.nuvol.com/noticies/els-sopars-delodissea-de-la-ma-den-joma>. 
recitació o d'improvisació oral a partir d'un relat previ que no es pot canviar- i fins i tot la capacitat imaginativa de creació lliure, a partir de la cuina. Encara que en el cas de Joma l'experiència és el resultat d'una acció individual de l'artista juntament amb una creació singular de la cuinera Parellada, en una adaptació amb finalitats didàctiques és un tipus d'experiència que es presta al treball en equip i a l'aprenentatge de grup. A l'aula, hom pot prescindir de l'element gastronòmic, però es pot crear un treball cooperatiu entre les classes de plàstica, les de grec i les de literatura o llengua catalana, per exemple, de manera que es combini la recitació del poema (o d'un episodi del poema, les Sirenes, o Polifem, o Circe, o els Feacis, o la mort dels pretendents) en vers grec, en traducció catalana, i en expressió lliure de l'obra (o sigui, composició a partir del que hom recorda però mitjançant la improvisació), amb el dibuix en directe (però pensat anteriorment) en tinta sobre una superfície blanca de paper. Això es pot fer en grups, donant a cada grup un passatge diferent de l'Odissea, de manera que col-lectivament, en acabar, s'hagin recitat i dibuixat les parts principals de l'obra. Si hi ha ensenyament del grec, és important que una part del treball sigui conèixer el text grec i aprendre'l (no cal entrar en les particularitats de la gramàtica homèrica si no formen part del programa, però hom es pot ajudar de la traducció per fer conèixer el grec); si l'assignatura és cultura clàssica, o només es fa llatí i no grec, es pot treballar en traducció o, fins i tot, eventualment es pot adaptar la mateixa idea a l'Eneida i treballar sobre el text de Virgili.

En els darrers temps, Joma ha emprès un altre projecte artístic, a partir de les Metamorfosis d'Ovidi. Anomenat TransformACCIONS, amb el subtítol "Òpera d'improvisació", és un treball fet a partir del llibre primer de les Metamorfosis d'Ovidi. El text és una adaptació catalana de l'obra llatina, refosa per Ramon Ferrer, ${ }^{13}$ i s'estrenà a Barcelona, al Centre Cultural Albareda del Poble Sec, el 3 de maig de 2018.

En aquest cas, Joma no es limita a treballar sobre una obra amb el pinzell, sinó que crea un muntatge global, a partir de la música, el cant, la dansa, la pintura, l'escultura i la veu, amb un equip de músics i actors. A mesura que, sobre l'escenari, els balladors dansen, o bé una veu recita el text ovidià, o els músics toquen, l'artista dibuixa sobre diferents suports, i el dibuix esdevé decorat de l'escenari alhora que expressió del text, o bé és projectat sobre una pantalla de fons (quan el dibuix està situat sobre el timbal, i alhora és percussió i dibuix). ${ }^{14}$

De fet, aquí Joma encunya el terme "desdibuix", per definir el caos inicial del principi del món, i treballar a partir del dibuix que crea i del dibuix que s'esborra, davant del públic, i durant tot l'espectacle juga amb aquests dos

\footnotetext{
13 Vegeu-ne el programa, amb el text de les intervencions, a <https://ajuntament.barcelona.cat/ ccivics/files/1524826507_TransformACCIONS_Programa.pdf $>$.

$14<$ https://youtu.be/rvQspl9pgdk>.
} 
conceptes. La música, el cant, la recitació, la dansa i el dibuix creat o esborrat, juntament amb unes escultures fetes per l'artista (grans caps o la imatge d'Argos en tres dimensions) creen un espectacle global de gran vistositat, però la voluntat de l'artista és fer reflexionar a través d'aquesta experiència creativa.

Com que el temps disponible no permet resseguir tot el llibre primer d'Ovidi, l'artista ha fet una tria. El caos inicial va seguit d'un text sobre el diluvi i la repoblació amb humans a partir de Deucalió i Pirra. Després, Pitó, el llorer (l'episodi de Dafne i Apol-lo), Argos i el mite de Pan i Siringa (fig. 4 i 5). Això li permet fer una crítica dels models que presenta la literatura antiga. Les històries de Dafne empaitada per Apol·lo, d'Io vigilada per Argos o de Siringa encalçada per Pan li permeten preguntar-se sobre els models que imposa la tradició literària i introduir-hi una perspectiva de gènere. La seducció dels déus, per ben explicada i poètica que sigui, no deixa de ser una imposició o una obligació; per tant, podem mirar la poesia des d'un altre angle. ${ }^{15}$ Pan diu, en el text ovidià adaptat, "nosaltres mantindrem sempre aquesta conversa", perquè la noia ha estat transformada en flauta que el déu fa sonar. Vol dir això que aquest estar junts per sempre és per obligació? I quina idea d'estar junts és el fet que un bufi i l'altra soni per força? Aquesta és precisament la pregunta que es fa l'artista al llarg de l'obra i posa en evidència la desigualtat d'aquests models de seducció divina i la situació de víctima de la dona assetjada.

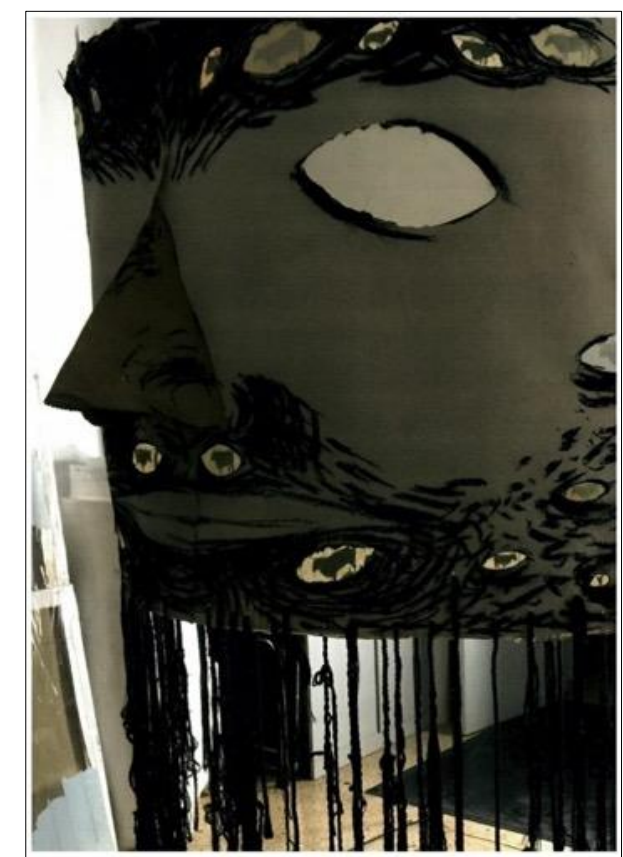

Fig. 4. Argos, el vigilant que no dorm. TransformACCIONS. Foto: Joma.

Per acabar-ho de destacar, el final d'aquesta "òpera d'improvisació" fa realment honor al seu nom. Fora ja del text original del poeta llatí, la persona que recita en el cas explicat, una dona- improvisa en una escena final en què es barreja

\footnotetext{
${ }^{15}$ Apol-lo repta Cupido: <https://youtu.be/BAtEnXK2GzA>.
} 
una música frenètica, la percussió i el dibuix cada cop més negre de Joma, en una mena de retorn al caos inicial de l'obra. En la representació que vam observar aquesta improvisació repetia les frases relatives a la persecució, juntament amb crits de "No és No", "Sempre?" i d'altres.

Per a Joma, aquesta és la lectura del final de l'espectacle: les històries d'Ovidi, en el fons, són assetjaments. Cada dia hom llegeix al diari històries semblants, perquè formen part del llenguatge des de sempre. L'objectiu de l'espectacle és preguntar-se per què hom es pot sentir fascinat per la figura i la música de Pan i no preguntar-se per l'origen de la flauta de Pan, o sigui, aquesta Siringa transformada a desgrat seu en instrument musical. Ell mateix explica ${ }^{16}$ que una solució possible seria una mena de correcció política que evités el conflicte, o bé oblidar els textos, directament. Una altra solució -la que ell adopta- és pensar que aquests textos estan a l'origen de la nostra cultura, i fer-ne una lectura en clau de gènere. De cap manera no s'ha de renunciar a aquests textos, que són d'una bellesa poètica incomparable, però sí que cal manifestar la tensió que provoquen i reflexionar sobre aquesta tensió. No és el primer que reflexiona sobre el gènere en els mites clàssics i de fet hi ha d'altres iniciatives, acadèmiques i literàries, que han qüestionat la mitologia tal com l'hem rebuda, perquè hi ha tota una tendència a qüestionar les dades de la tradició històrica i artística des de la perspectiva de gènere, però és interessant veure que Joma, des de la creació, no rebutja el text antic, sinó que el reivindica tant per crear art com per crear pensament crític.

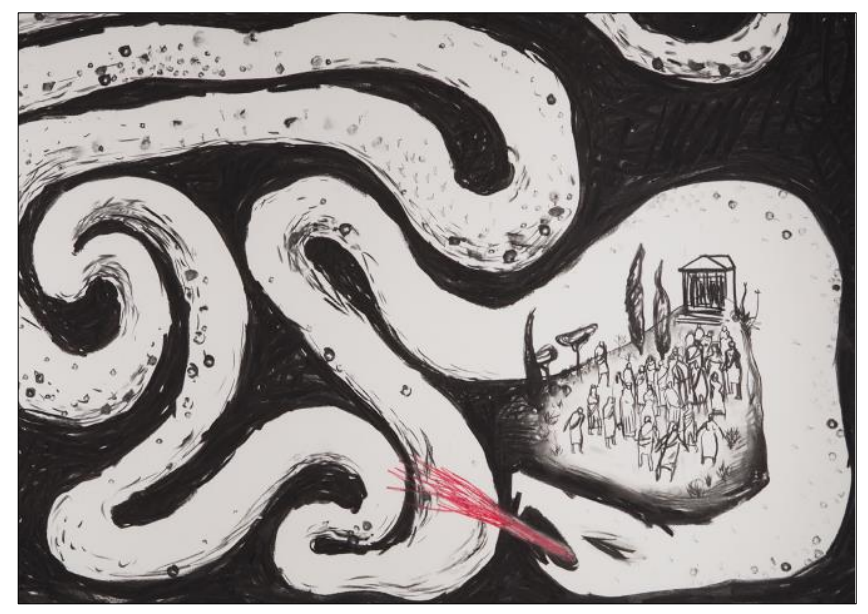

Fig. 5. Pitó. TransformACCIONS. Foto: Joma.

Per a ell, la idea fonamental, en aquesta representació, és la "llavor discordant dins de les coses mal aparellades". Aquesta llavor discordant és encara a dintre de totes les coses, i l'experiència artística la fa aflorar i ens fa adonar-nos-en.

La voluntat de Joma és de discutir visualment els components que ens disgusten amb la mentalitat del segle XXI, però sense discutir la bellesa de les

\footnotetext{
${ }^{16}$ En una llarga entrevista que li vaig fer l'estiu del 2018, al seu taller de Barcelona, amb motiu d'aquest estudi.
} 
imatges i del llenguatge, que cal recuperar i conèixer com a part de la nostra tradició. A partir d'aquí, hi ha moltes possibilitats de reflexionar sobre textos clàssics i fer-ho amb l'expressió artística que també crea bellesa. A l'aula es pot combinar la reflexió sobre un mite concret, l'aprenentatge del text (Ovidi, Homer, Apol-lodor, Virgili, etc.), la representació plàstica, ja sigui amb escultura o pintura, la dramatització teatral (escrivint el guió els alumnes mateixos, o bé recitant versos d'Ovidi o de Virgili) i la música (sobretot amb l'ús de flauta i percussió, habituals en moltes escoles). El component essencial aquí és la dramatització: els alumnes poden escriure una breu peça basada en un autor clàssic, sobre un mite, amb cites antigues, cercar-hi música adient, tocar-la (almenys la melodia o un arranjament fet a classe de música), crear el decorat, etc., en treball cooperatiu de llengua, literatura, assignatures clàssiques, plàstica i música. Eventualment, podria resultar un excel-lent treball per a un crèdit de síntesi.

Joma ha continuat el tema de les Metamorfosis en altres presentacions artístiques. Així, el maig de 2019, a Can Fabra, presenta un "Concert pictòric", 17 una acció amb dibuixos (sempre fets en directe davant del públic) relatius als mites de Narcís, Pan, Bacus, Faetó, Níobe i Aretusa, entre d'altres, i música interpretada per Tere Galceran, que toca amb la flauta melodies de Britten, Honegger, Debussy i Graves. La creativitat artística torna a conjugar-se amb l'esperit crític, en la tria dels mites i en la realització del dibuix, que presenta el conflicte, a més d'introduir el valor de la música, que no és elegida a l'atzar, sinó d'acord amb els mites (el Prélude à l'après-midi d'un faune, de Debussy, en relació amb Pan, per exemple). Aquest espectacle, amb les variants que proporciona la realització en directe, s'havia presentat l'octubre del 2018 al Taller de Músics de Barcelona, en el marc del festival "Connexions". ${ }^{18}$

Joma no s'ha dedicat només a la reinterpretació dels clàssics, sinó que té una llarga trajectòria artística ${ }^{19}$ que mereix un estudi a part i que no és l'objecte $\mathrm{d}$ 'aquest article. Tanmateix, el seu interès pel mon de la literatura grecollatina l'ha dut a inserir-la entre els motius habituals de creació pictòrica, amb combinació sobretot de la música entre altres arts. Això permet, d'una banda, posar en valor la bellesa i l'atractiu de la poesia antiga per als que conreen altres disciplines, sense necessitat que hi hagi forçosament una instrucció o una especialització històrica o filològica, i de l'altra, i molt més important, desenvolupar una mirada crítica sobre aquesta tradició poètica i sobre el llenguatge que ens ha estat transmès. Els antics serveixen per al nostre gaudi estètic i per a la creació imaginativa, però serveixen, sobretot, per qüestionar-

\footnotetext{
$17<$ www.facebook.com/Bibcanfabra/videos/321997621810762>.

$18<$ https://youtu.be/_Fps6xqRhvk>.

${ }^{19}$ L'abril del 2019 se celebrà una exposició, amb motiu dels 50 anys del seu primer dibuix, sobre les fonts que havien nodrit la seva capacitat artística: Exposició “De les arrels", a Can Fabra: <https://ajuntament.barcelona.cat/biblioteques/bibcanfabra/ca/noticia/joma-de-les-arrelsals-brots-nous_789222>, <https://youtu.be/TKOpux_LPn0>i $<$ https://youtu.be/-4W_cImm0XQ $>$.
} 
nos el món que hem rebut i en què actuem i creem. El llenguatge transmès és el que ens ha portat a uns comportaments i actituds que donem com a vàlids fins al dia que ens preguntem d'on venen i quin és el seu sentit. El text i la creació artística, doncs, ens serveixen per canviar la manera de mirar, adoptar una perspectiva nova, també de gènere, i tornar a formular el propi llenguatge i la manera de viure. Es tracta de tradició clàssica en el millor sentit del terme, no la que transmet, sinó la que reinterpreta i repensa, de manera que esdevé art i alhora incideix en la vida quotidiana.

La darrera experiència clàssica de l'artista -almenys, en el moment de tancar aquest article- consisteix en una plaquette sobre Polifem, amb text de Riba i una recreació visual de Joma. ${ }^{20}$ Després d'una introducció de l'artista, es publica el text d'Odissea 9.105-566, en la darrera versió de Carles Riba, i una llarga il·lustració de l'episodi en leporello o llibre acordió. Aquesta obreta, a més d'oferir per si mateixa un objecte d'estudi, ja que el dibuix és complex i permet diverses mirades $\mathrm{i}$ anàlisis plàstiques, $\mathrm{i}$ el text és prou ric (seria una bona idea treballar-lo a classe en relació amb el dibuix i després convidar l'artista per parlar-ne), obre la possibilitat a un altre tipus de treball cooperatiu sobre textos: la lectura d'un episodi homèric, o d'un mite, o d'un text d'Ovidi o de Virgili, l'estudi del text, la traducció (si és el cas) o l'accés a traduccions publicades existents (i la valoració crítica corresponent de cada una d'elles d'acord amb criteris d'estil, llengua, etc.) i la il-lustració del text, a partir de creacions successives sobre el mateix suport de paper plegat que dona lloc a un desplegable creat collectivament. Preguntar-se pel sentit de la creació artística en relació amb el text i per què s'han dut a terme uns dibuixos i no uns altres i quins eren els objectius de cadascú pot donar peu a una reflexió no solament literària, sinó també, i sobretot, ètica i filosòfica, sempre, doncs, interdisciplinària.

Per això creiem que l'activitat creadora de Joma, que no s'ha pas estroncat aquí i que promet altres iniciatives suggeridores en el futur, té un ampli valor per als especialistes de les disciplines clàssiques als centres d'ensenyament. No solament permet el gaudi directe de l'art sobre tema grecollatí, sinó que introdueix, sobretot, l'esperit crític i, a partir d'aquí, iniciatives pedagògiques, literàries, artístiques i fins i tot filosòfiques amb públics de tota mena, ja sigui en etapes formatives obligatòries com amb públic adult que mai no s'ha acostat als clàssics o que no ha tingut ocasió de reflexionar-hi. O bé el professor pot adaptar a l'aula aquestes experiències amb altres textos i escenaris, o bé pot directament convidar l'artista a realitzar una creació en viu davant de l'alumnat del centre i entrar en un diàleg, a partir de l'estudi previ de la seva creació artística, per tal de permetre l'aprofundiment sobre el pensament crític i el valor de l'art com a construcció de la societat. ${ }^{21}$

\footnotetext{
${ }^{20}$ Joma (2019), Polifem, el beverri. Amb el cant del Cíclop de l'Odissea, en versió de Carles Riba, Alella, ViBop.

${ }^{21}$ Si algú està interessat a contactar amb l'artista, ho pot fer a l'adreça <joma.correu@gmail.com>.
} 